\title{
Modeling of Circulating Flow in RH Degassing Vessel Water Model Designed for Two- and Multi-legs Operations
}

\author{
Baokuan LI and Fumitaka TSUKIHASHI ${ }^{11}$
}

Department of Thermal Engineering, The School of Materials and Metallurgy, Northeastern University, Shenyang, 110006 , China; visiting researcher in the Department of Materials Engineering, Graduate School of Engineering, The University of Tokyo, Hongo, Bunkyo-ku, Tokyo 113-8656 Japan. Science, The University of Tokyo, Hongo, Bunkyo-ku, Tokyo 113-0033, Japan.

(Received on May 8, 2000; accepted in final form on August 16, 2000)

\begin{abstract}
A mathematical model has been developed to analyze the circulating flow characteristics in $\mathrm{RH}$ Degassing vessel designed for two- and multi- legs system. The homogeneous model with the spatially variable density was used to simulate gas-liquid flow in up-legs. The difference of density between pure liquid and gas-liquid was considered to be a driving force of circulation flow. The volume fraction of gas was obtained by modifying the gas plume model of the stirred ladle. The complicated geometry including ladle, vacuum, up-legs, and down-leg was considered by incorporation of blockage technique. Numerical calculations of the circulating flow have been conducted for the water model of $\mathrm{RH}$ degassing vessel with twoand multi-legs with changing the air flowrates from 5 to $35 \mathrm{l} / \mathrm{min}$. Computed velocities at the exit of downleg agree well with the observed data available in the literature. The momentum transport in $\mathrm{RH}$ degassing vessel with multi-legs will be larger than that with two-legs. This is justified based on fact that the velocities in $\mathrm{RH}$ degassing vessel with multi- legs tend to be uniform, i.e. the mean velocity of bulk in a ladle is remarkably larger than that in two-legs. Simulated transient concentration profile of the tracer from top surface to interior shows clearly the difference of flow characteristics between two- and multi-legs $\mathrm{RH}$ degassing vessels.
\end{abstract}

KEY WORDS: RH degassing vessel; circulating flow; modeling; two- and multi-legs operations.

\section{Introduction}

Many researches ${ }^{1-3)}$ on the circulation flow phenomena in RH degassing vessel have been conducted to improve the efficiency of secondary steelmaking. Recently, from the standpoint of environmental issue, the study on the long life of $\mathrm{RH}$ equipment is more and more emphasized. One of problems of impeding long life is corrosion of ladle wall by slag. For conventional RH degassing vessel with two legs, the slag is easy to be stagnant at wall near down-leg. Obata et $a l^{4-6)}$ proposed a new RH degassing vessel with multilegs. The down-leg is placed at the center of ladle and three up-legs are used to adjust the velocity distribution and prevent corrosion of wall as shown in Fig. 1. The result of water model experiment shows that the circulation flow rate of RH with multi-legs is larger than that with two-legs. ${ }^{5)}$ It is important to understand the velocity distribution and turbulent kinetic energy of molten steel in the RH degassing vessel with multi- legs for improving refining efficiency and life of refractory. However, experimental measurement provides only local and finite information in the whole flow field.

The purpose of the present study is to develop a mathematical model for the circulating flow in $\mathrm{RH}$ equipment including ladle, vacuum vessel, up-leg, and down-leg. Furthermore, this model is used to simulate the flow char-

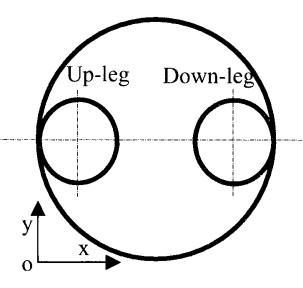

(a) With two legs, diameter of legs is $80 \mathrm{~mm}$

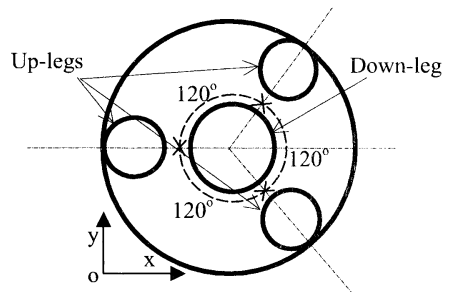

(b) With multi-legs, diameter of up-legs is $50 \mathrm{~mm}$, down-leg is $80 \mathrm{~mm}$

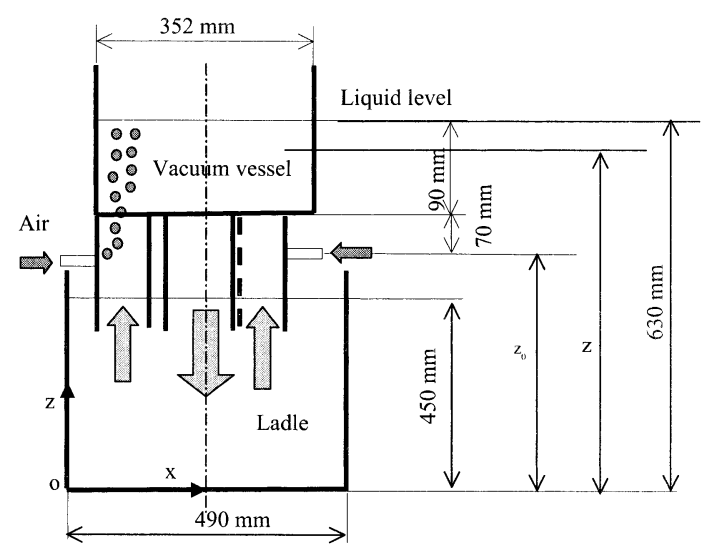

Fig. 1. Schematic of water model of RH degassing vessel in horizontal and vertical view, (a) two-legs and (b) multi- legs. 
acteristics of the water model of the RH degassing vessel with two- and multi- legs.

\section{Mathematical Model}

\subsection{Flow Equation for Molten Steel}

\subsubsection{Governing Equations}

The buoyancy force of injected gas bubbles induces the circulating flow of steel. The homogeneous model with spatially variable density is used to simulate the gas-liquid flow. The force at the interface between gas bubbles and liquid disappears automatically. Since the difference of density between gas and liquid is very large, the gas-liquid system is not in equilibrium. Therefore, the difference between static pressure and the pressure in a bubble is not taken into account for the model. The molten steel flow is governed by the equations of mass conservation, momentum conservation, and turbulence model. The equations in Cartesian coordinate system are written in three-dimensional common form as follows.

$$
\begin{aligned}
& \frac{\partial(\rho u \phi)}{\partial x}+\frac{\partial(\rho v \phi)}{\partial y}+\frac{\partial(\rho w \phi)}{\partial z} \\
& \quad=\frac{\partial}{\partial x}\left(\Gamma \frac{\partial \phi}{\partial x}\right)+\frac{\partial}{\partial y}\left(\Gamma \frac{\partial \phi}{\partial y}\right)+\frac{\partial}{\partial z}\left(\Gamma \frac{\partial \phi}{\partial z}\right)+S_{\phi} \cdots
\end{aligned}
$$

The equations for each variable are shown in Table 1.

Density of gas-liquid flow zone, $\rho$, is calculated by homogeneous fluid model as expressed in Eq. (2),

$$
\rho=\rho_{\mathrm{g}} \alpha+(1-\alpha) \rho_{\text {liq }} .
$$

Where the volume fraction of gas, $\alpha$, can be obtained as described in Sec. 2.1.2.

Although the gas-liquid plume is included in flow field, the standard $k-\varepsilon$ two-equation turbulence model ${ }^{8)}$ is used to solve the effective viscosity, $\mu_{\mathrm{e}}$, since the turbulent flow model including two phases is not available. The reason is that the effect of gas plume formation on the turbulent viscosity has partly been taken into account by using the variable density, and the volume fraction of gas is relatively small in the bulk fluid.

\subsubsection{Model for the Gas-Liquid System}

The compressed gas is injected into vessel through four nozzles located iso-angularly at wall of up-legs. The difference of density between pure liquid and gas plume produces a circulation flow in the RH degassing vessel.

Castillejos and Brimacombe ${ }^{7)}$ proposed a relationship between the axial gas fraction and half-value radius in a ladle as Eq. (3).

$$
\frac{\alpha_{L}}{\alpha_{\max }}=\exp \left(-0.7\left(\frac{r}{r_{\alpha_{\max 2}}}\right)^{2.4}\right)
$$

Where $\alpha_{\mathrm{L}}$ is the gas volume fraction in case that the reduced pressure is not considered, $\alpha_{\max }$ is the maximum value at the center of gas plume. The half-value radius $r_{\alpha_{\max 2}}$ is the distance from the axis of symmetry to the position where the gas fraction is half of the maximum value. The $\alpha_{\max }$ and $r_{\alpha_{\max 2}}$ are the function of flowrate of air and inlet diameter as reported in the literature. ${ }^{7)}$

Equation (3) obtained for the ladle injection is applied to the injection of the RH process. The process of gas injection into RH vessel is different from that into a ladle. First, four or more nozzles are used to inject gas into the up-legs from side wall. Second, the effect of reduced pressure should be taken into account. When the gas flow rate exceeds a critical value $(15 \mathrm{l} / \mathrm{min})$, a gas plume structure of ladle-shaped vessel in upper part from A section as shown in Fig. 2 can be observed as reported by Obata et al. ${ }^{5)}$ On the other hand, the gas bubble obeys the ideal gases law. If an isothermal process for rising of gas bubbles is assumed, the equation of state of a gas bubble is expressed as Eq. (4):

$$
p V=p_{0} V_{0}
$$

Where $p_{0}$ and $V_{0}$ are the pressure and volume of gas bubble at the nozzle outlet respectively. The gas volume in a finite

\begin{tabular}{|c|c|c|c|}
\hline & $\phi$ & $\Gamma$ & $S_{\phi}$ \\
\hline Continuity & 1 & 0 & 0 \\
\hline $\mathrm{x}$-direction momentum & $u$ & $\mu_{\mathrm{e}}$ & $\mathrm{S}_{\mathrm{u}}=\frac{\partial}{\partial \mathrm{x}}\left(\mu_{\mathrm{e}} \frac{\partial \mathrm{u}}{\partial \mathrm{x}}\right)+\frac{\partial}{\partial \mathrm{y}}\left(\mu_{\mathrm{c}} \frac{\partial \mathrm{v}}{\partial \mathrm{x}}\right)+\frac{\partial}{\partial \mathrm{z}}\left(\mu_{\mathrm{e}} \frac{\partial \mathrm{w}}{\partial \mathrm{x}}\right)-\frac{\partial \mathrm{p}}{\partial \mathrm{x}}$ \\
\hline y-direction momentum & V & $\mu_{\mathrm{e}}$ & $S_{v}=\frac{\partial}{\partial x}\left(\mu_{e} \frac{\partial u}{\partial y}\right)+\frac{\partial}{\partial y}\left(\mu_{c} \frac{\partial v}{\partial y}\right)+\frac{\partial}{\partial z}\left(\mu_{c} \frac{\partial w}{\partial y}\right)-\frac{\partial p}{\partial y}$ \\
\hline z-direction momentum & $w$ & $\mu_{\mathrm{e}}$ & $S_{w}=\frac{\partial}{\partial x}\left(\mu_{e} \frac{\partial u}{\partial z}\right)+\frac{\partial}{\partial y}\left(\mu_{e} \frac{\partial v}{\partial z}\right)+\frac{\partial}{\partial z}\left(\mu_{e} \frac{\partial w}{\partial z}\right)-\frac{\partial p}{\partial z}-\rho g$ \\
\hline $\begin{array}{l}\text { Turbulent kinetic } \\
\text { Energy }\end{array}$ & $k$ & $\frac{\mu_{t}}{\sigma_{k}}$ & $\begin{aligned} S_{k} & =G-\rho \varepsilon \\
G & =\mu_{,}\left\{2\left(\frac{\partial u}{\partial x}\right)^{2}+2\left(\frac{\partial v}{\partial y}\right)^{2}+2\left(\frac{\partial w}{\partial z}\right)^{2}\right. \\
& \left.+\left(\frac{\partial u}{\partial y}+\frac{\partial v}{\partial x}\right)^{2}+\left(\frac{\partial u}{\partial z}+\frac{\partial w}{\partial x}\right)^{2}+\left(\frac{\partial w}{\partial y}+\frac{\partial v}{\partial z}\right)^{2}\right\}\end{aligned}$ \\
\hline $\begin{array}{l}\text { Dissipation rate of } \\
\text { turbulent kinetic energy }\end{array}$ & $\varepsilon$ & $\frac{\mu_{t}}{\sigma_{\varepsilon}}$ & $S_{\varepsilon}=C_{1} G \frac{\varepsilon}{k}-C_{2} \rho \frac{\varepsilon^{2}}{k}$ \\
\hline \multicolumn{4}{|c|}{ Effective viscosity ${ }^{[8]}: \quad \mu_{l}=\frac{C_{\mu} \rho k^{2}}{\varepsilon}, \mu_{\mathrm{e}}=\mu_{\mathrm{L}}+\mu_{l}$, } \\
\hline \multicolumn{4}{|c|}{$C_{1}=1.44, C_{2}=1.92, C_{\mu}=0.09, \sigma_{k}=1.0, \sigma_{\varepsilon}=1.3, \sigma_{C}=1.0$} \\
\hline
\end{tabular}
volume can be calculated by the gas volume fraction.

$$
\alpha=\frac{p_{0}}{p} \alpha_{\mathrm{L}}
$$

Table 1. Variables in the common equation. 
Pressure in Eq. (5) can be approximately expressed as $p=$ $p_{\mathrm{V}}+\rho g(H-z)$ and $p_{0}=p_{\mathrm{V}}+\rho g\left(H-z_{0}\right)$, where $p_{\mathrm{V}}$ is the pressure in vacuum vessel, $H$ is the height of liquid in the RH vessel and $z_{0}$ is the height of nozzles as shown in Fig. 1. The bubble volume can expand to be ten times of the initial one at the nozzle exit where $p_{\mathrm{V}}$ is $1.33 \times 10^{2} \mathrm{~Pa}$ ( 1 Torr) and $H$ is 1.5 to $2.0 \mathrm{~m}$ for practical operation.

\subsubsection{Boundary Conditions}

As the fluctuation of free surface is neglected, the axial gradient of all variables at the free surface is equal to zero.

Velocity and turbulent kinetic energy at the solid wall are zero. Empirical "wall law" function is employed to define the tangential velocity, turbulent kinetic energy, and the rate of dissipation of turbulent kinetic energy at the grid nodes near wall.

The $\mathrm{P}$ is first node point from solid wall. If $\mathrm{P}$ is in turbulent zone, the logarithmic law is used to calculate the velocity at point $P$.

$$
u^{+}=\frac{1}{k} \ln y^{+}+B
$$

where $k=0.4-0.42, B=5.0-5.5$, the $y^{+}$is non-dimensional distance.

The other turbulent parameters are calculated as follows:

$$
\begin{aligned}
& k: \frac{\partial k}{\partial n}=0 ; \int_{0}^{y_{\mathrm{p}}} \varepsilon_{\mathrm{P}} d y=c_{\mu} k^{3 / 2} \ln \left(E y^{+}\right) / k \\
& \varepsilon: \varepsilon_{\mathrm{P}}=c_{\mu}^{3 / 4} k_{\mathrm{P}}^{3 / 2} /\left(k y_{\mathrm{P}}\right) \\
& v_{\mathrm{e}}=\frac{\mu_{\mathrm{e}}}{\rho}: v_{\mathrm{e}}=\frac{c_{\mu}^{1 / 4} k_{\mathrm{P}}^{1 / 2} k y_{\mathrm{P}}}{\ln \left(E y^{+}\right)} \quad y^{+}>11.63 \\
& v_{\mathrm{L}}=\frac{\mu_{\mathrm{L}}}{\rho}: v_{\mathrm{e}}=v_{\mathrm{L}} \quad y^{+} \leq 11.63 \\
& y^{+}, u^{+}: y^{+}=\frac{u^{*} y_{\mathrm{P}}}{v_{\mathrm{L}}}, u^{+}=V_{\mathrm{P}} k / \ln \left(\frac{E u^{*} y_{\mathrm{P}}}{v_{\mathrm{L}}}\right) .
\end{aligned}
$$

Where $V_{\mathrm{P}}$ is the velocity at the point $\mathrm{P}, u^{*}$ is the friction velocity at wall, $y_{\mathrm{P}}$ is distance from solid wall, and $E=8.8-$ 9.0.

\subsection{Tracer transport}

Although the decarburization rate depends on both of the mass transfer and chemical reaction rates, only mass transfer is considered in the following analysis. The transient tracer transfer with convection and diffusion can be expressed by Eq. (7):

$$
\begin{aligned}
& \frac{\partial\left(\rho C^{\prime}\right)}{\partial t}+u \frac{\partial\left(\rho C^{\prime}\right)}{\partial x}+v \frac{\partial\left(\rho C^{\prime}\right)}{\partial y}+w \frac{\partial\left(\rho C^{\prime}\right)}{\partial z} \\
& =\frac{\partial}{\partial x}\left(\frac{\mu_{\mathrm{t}}}{\sigma_{C}} \frac{\partial \rho C^{\prime}}{\partial x}\right)+\frac{\partial}{\partial y}\left(\frac{\mu_{\mathrm{t}}}{\sigma_{C}} \frac{\partial \rho C^{\prime}}{\partial y}\right)+\frac{\partial}{\partial z}\left(\frac{\mu_{\mathrm{t}}}{\sigma_{C}} \frac{\partial \rho C^{\prime}}{\partial z}\right)
\end{aligned}
$$

The dimensionless expression (8) is same as Eq. (7).

$$
\frac{\partial(\rho C)}{\partial t}+u \frac{\partial(\rho C)}{\partial x}+v \frac{\partial(\rho C)}{\partial y}+w \frac{\partial(\rho C)}{\partial z}
$$

$$
=\frac{\partial}{\partial x}\left(\frac{\mu_{\mathrm{t}}}{\sigma_{C}} \frac{\partial C}{\partial x}\right)+\frac{\partial}{\partial y}\left(\frac{\mu_{\mathrm{t}}}{\sigma_{C}} \frac{\partial C}{\partial y}\right)+\frac{\partial}{\partial z}\left(\frac{\mu_{\mathrm{t}}}{\sigma_{C}} \frac{\partial C}{\partial z}\right)
$$

Where, $C=C^{\prime} / C_{0}, C_{0}$ is the maximum concentration.

If the decarburization reaction is assumed to take place only at top surface of molten steel, the initial conditions are expressed as follows:

$t=0 \quad C=0$, in the fluid, $C=1$, at the top surface.

The boundary conditions at the solid wall are expressed as $\partial(C) / \partial n=0$.

\subsection{Solution method}

\subsubsection{Blockage technique for complex RH system}

The existence of upper degassing vessel and legs has been ignored in the previous models. ${ }^{1-3)}$ In the present analysis, the model includes whole RH system including ladle, degassing vessel, and legs. The complicated geometry is analyzed by blockage technique, which creates no extra numerical difficulty.

The volume factor $f_{\mathrm{V}}$ and area factor $f_{\mathrm{A}}$ are defined as follows, respectively:

$$
f_{\mathrm{V}}=\left\{\begin{array}{l}
1, \text { for fluid } \\
0, \text { for solid }
\end{array} \text { and } f_{\mathrm{A}}=\left\{\begin{array}{l}
1, \text { for fluid } \\
0, \text { for solid }
\end{array}\right.\right.
$$

The discretization equations associated with these factors can be expressed by Eq. (9):

$$
\begin{aligned}
& \frac{\partial}{\partial t}\left(\rho \phi \cdot V \cdot f_{\mathrm{V}}\right)_{\mathrm{P}} \\
& \quad+\sum_{\mathrm{e}, \mathrm{w}, \mathrm{n}, \mathrm{s}, \mathrm{h}, 1}\left[\left(\rho \vec{V} \phi-\Gamma_{\phi} \operatorname{grad} \phi\right) \cdot A \cdot f_{\mathrm{A}}\right]_{i}=\left(S_{\phi} \cdot V \cdot f_{\mathrm{V}}\right)_{\mathrm{P}} \cdots
\end{aligned}
$$

where, $\Gamma_{\phi}$ is exchange coefficient.

\subsubsection{Conditions of calculation and algorithm}

The geometrical parameters of water model with twoand multi-legs are shown in Fig. 1. The size of model is about one-tenth of the RH system. For the new RH system with multi-legs, the diameter of up-legs is $50 \mathrm{~mm}$, and down-leg is $80 \mathrm{~mm}$. The sum of the total horizontal section area of three up-legs is approximately equal to the section area of down-leg. For the conventional RH system with two legs, the diameter of legs is $80 \mathrm{~mm}$. The air flowrate varies

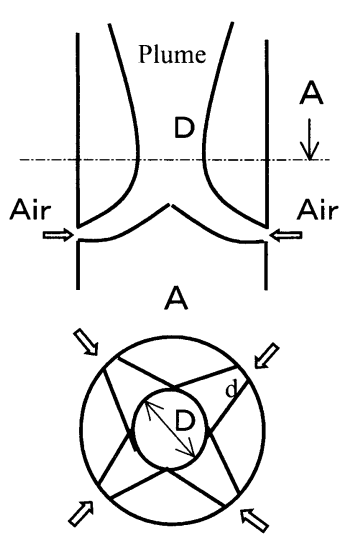

Fig. 2. The air plume structure in an up-leg. 
from 5 to $35 \mathrm{l} / \mathrm{min}$.

A finite volume method has been chosen for this calculation of complicated system. The non-linear simultaneous equations are solved by using SIMPLEC algorithm. A main mesh system of $42 \times 42 \times 60$ is used to divide the calculation domain. A combination of Alternating-Direction-semiImplicit iteration scheme (ADI) and block correction is used to solve the discretized algebraic equations. When the relative difference between successive solutions is smaller than $0.05 \%$, it is decided that the converged velocity and turbulence is obtained. Over 3000 iterations are required to achieve convergence starting with initial zero velocity.

\section{Results and Discussion}

Obata et $\mathrm{al}^{5 \text { ) }}$ have measured the velocity distribution at the outlet of down-leg of water model with two- and multilegs. These results are compared with the present mathematical model. To compare the calculated velocities with measured ones at the outlet of the down-leg, the dimensionless velocity and distance are defined as Eqs. (10) and (11):

$$
\begin{gathered}
\bar{V}=\frac{w}{w_{\max }}, \bar{Y}=\frac{1}{D_{1}}\left(x+D_{1}-D_{0}\right) \\
\text { for the two- legs RH system, }
\end{gathered}
$$

$$
\bar{V}=\frac{w}{w_{\max }}, \bar{Y}=\frac{1}{D_{1}}\left[x+\frac{1}{2}\left(D_{1}-D_{0}\right)\right]
$$

for the multi- legs RH system,

where, $w_{\max }$ is the maximum velocity at the outlet of the down-leg, $D_{0}$ is diameter of the vessel, and $D_{1}$ is diameter of the down-leg.

Figures 3 and $\mathbf{4}$ show the comparison of vertical velocities between calculated and measured at the outlet of downleg of RH degassing vessel with two- and multi-legs. It can be observed that calculated values agree well with measured ones. The small difference may be caused by the overestimation of turbulent viscosity by the standard $k-\varepsilon$ turbulence model.

The calculated and measured circulation flow rates of water model are shown in Fig. 5. The flow rate through down-leg is set as the same as circulation flow rate in the $\mathrm{RH}$ vessel. The calculated circulation flow rates are somewhat larger than measured ones, since an explanation is that the top surface fluctuation is neglected in calculation. The trend of flow rate with the gas injection coincides with that of measurement. Obviously, the more strong circulating flow in the RH degassing vessel with multi-legs can be observed.

To understand the flow characteristics of two- and multilegs RH degassing vessel, the velocity fields are calculated. Figure 6 shows the velocity vectors on vertical and horizontal sections of RH vessel with two legs. The velocity vectors with multi- legs are shown in Fig. 7. The maximum velocity $(0.515 \mathrm{~m} / \mathrm{s})$ of the multi- legs is smaller than that of two- legs $(0.781 \mathrm{~m} / \mathrm{s})$. The velocity profile with the multilegs is uniform, i.e. the bulk mean velocity in ladle is remarkably larger than that with two- legs. Figure 8 shows the distribution of the turbulent kinetic energy at main sections for two- and multi-legs system. A significant differ-

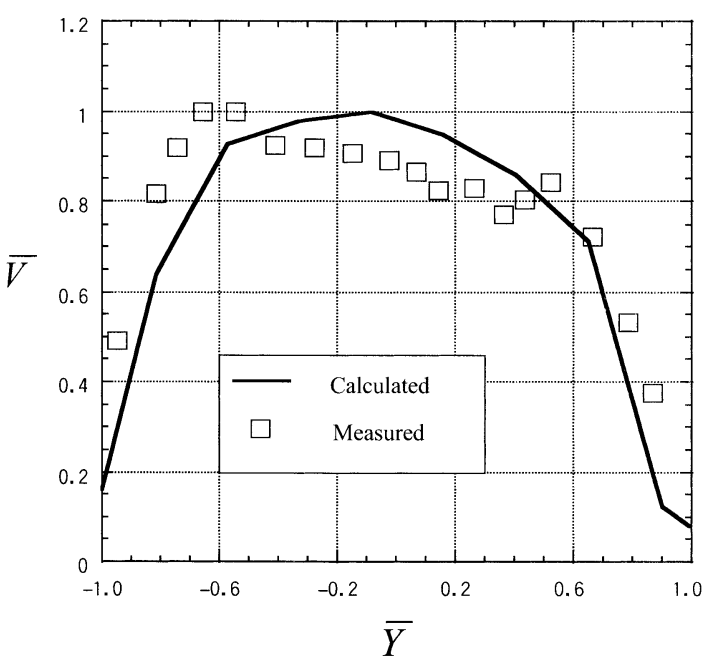

Fig. 3. Comparison of calculated velocity distribution with measured one at the outlet of down-leg of the two-legs of RH degassing vessel.

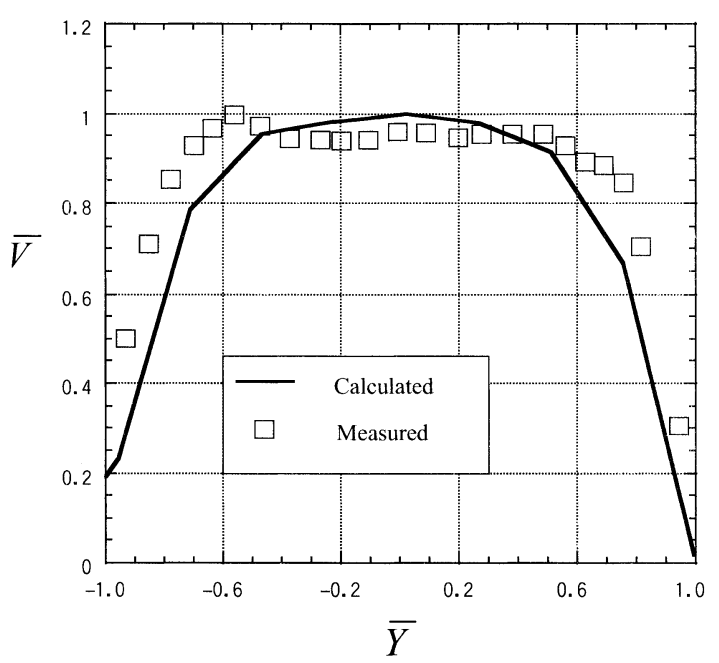

Fig. 4. Comparison of calculated velocity distribution with measured one at the outlet of down-leg of the multi-legs of $\mathrm{RH}$ degassing vessel.

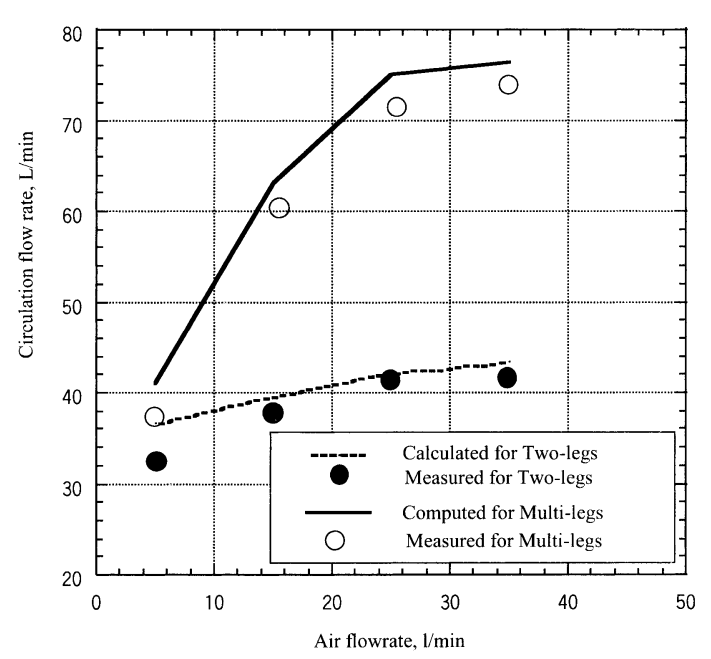

Fig. 5. Effect of the air flowrates on the circulation flow rates of water model of the RH degassing vessel. 


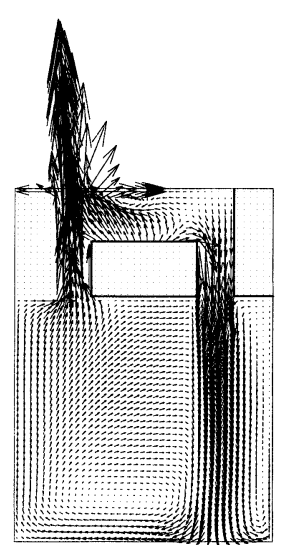

(a)

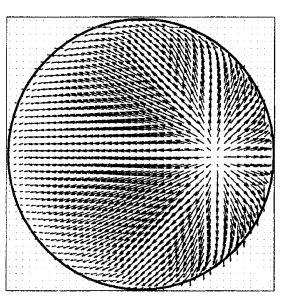

(c)

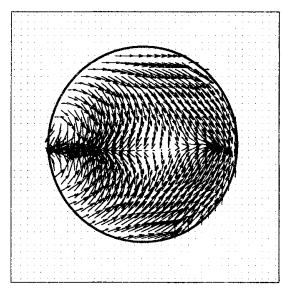

(e)

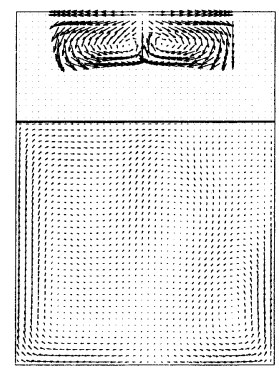

(b)

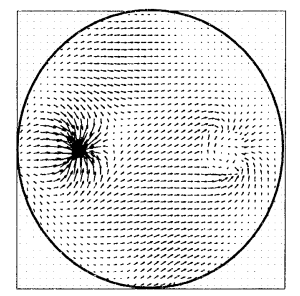

(d)

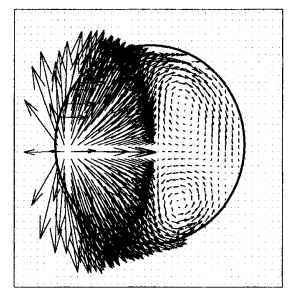

(f)

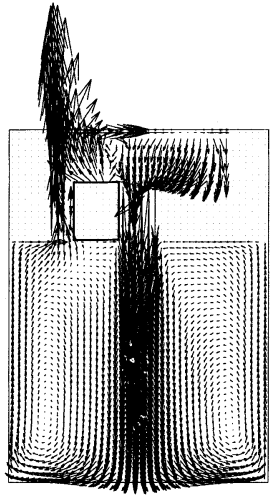

(a)

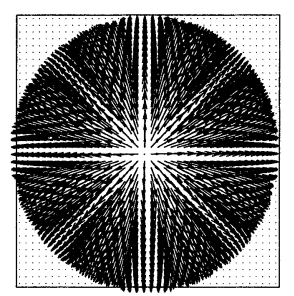

(c)

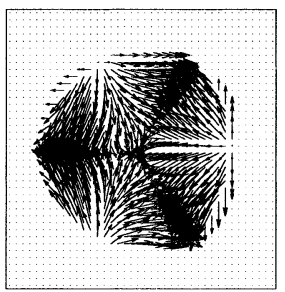

(e)

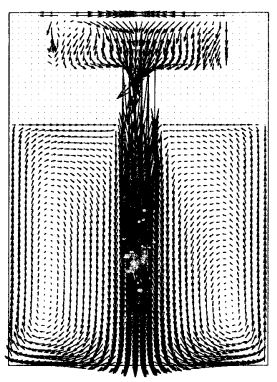

(b)

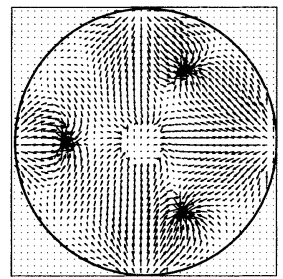

(d)

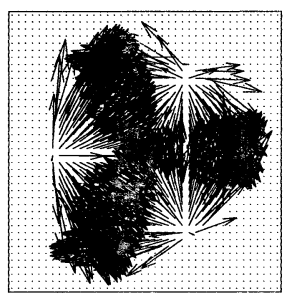

(f)

Fig. 6. Calculated velocity at sections of the two-legs system, the maximum velocity of (a) through (f) is $0.781 \mathrm{~m} / \mathrm{s}$.

(a) Main section, (b) perpendicular to main section, (c) bottom of ladle, (d) top of ladle, (e) bottom of vacuum chamber, and (f) free surface of vacuum chamber.

Fig. 7. Calculated velocity at sections of the multi-legs system, the maximum velocity of (a) through (f) is $0.515 \mathrm{~m} / \mathrm{s}$.

(a) Main section, (b) perpendicular to main section, (c) bottom of ladle, (d) top of ladle, (e) bottom of vacuum chamber, and (f) free surface of vacuum chamber.

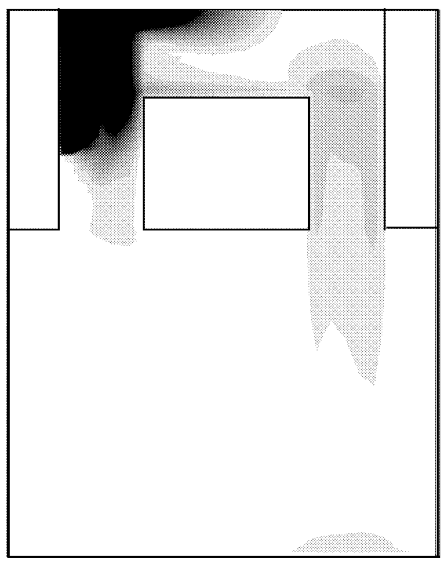

(a)
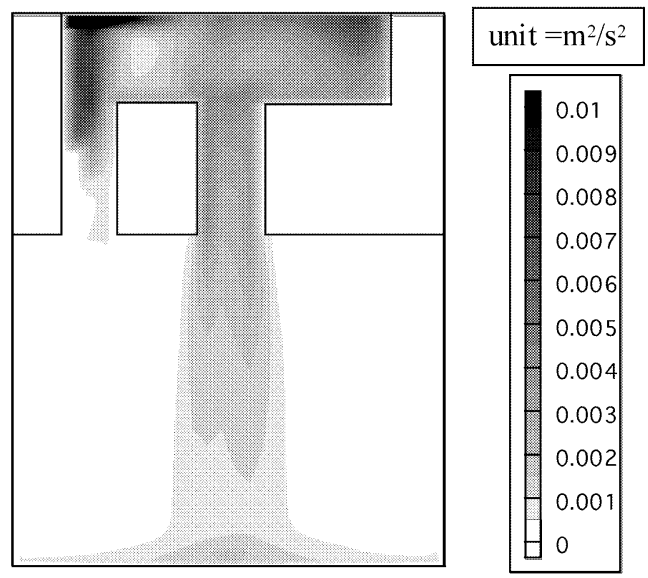

(b)

Fig. 8. Calculated turbulent kinetic energy (line interval is $0.001 \mathrm{~m}^{2} / \mathrm{s}^{2}$ ) at main section. (a) Two- and (b) multi-legs systems, air flowrate: $35 \mathrm{l} / \mathrm{min}$.

ence can be observed between two vessels. The turbulent kinetic energy is large only at upper part of up-leg with two-legs system. On the other hand, the turbulent kinetic energy distributed uniformly with multi- legs system. Figure 9 illustrates a comparison of the volume contained within isovelocity surface of $0.05 \mathrm{~m} / \mathrm{s}$ between two- and 

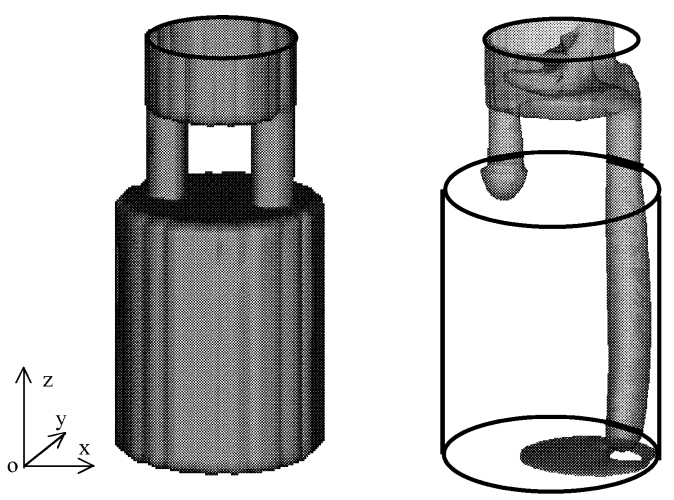

(a)
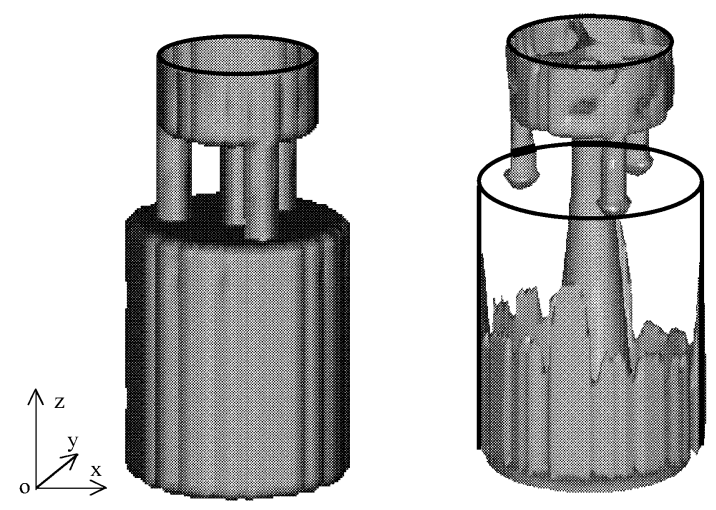

(b)

Fig. 9. Comparison of the iso-velocity surface $(=0.05 \mathrm{~m} / \mathrm{s})$ between (a) two- and (b) multi-legs systems, air flowrate: $35 \mathrm{l} / \mathrm{min}$. multi-legs when the air flowrate is $35 \mathrm{l} / \mathrm{min}$. Obviously, it is observed that the velocity is more than $0.05 \mathrm{~m} / \mathrm{s}$ in larger region of the multi-legs system compared with the two- legs system. Therefore, it can be concluded that the more momentum can be produced in the multi- legs system.

A schematic representation of air bubbles flow is shown in Fig. 10. The circulation flow is induced by the buoyancy force on gas bubbles, when gas bubbles float. The surrounding fluid fills the space occupied by the air bubbles previously generated. If large amount of air is injected into the one leg such as the two-legs RH system, the volume occupied by air bubbles prevents the fluid flowing through upleg. If air is injected through three-legs, the three up-leg space can allow more fluid flow. Therefore, the larger circulation flow rate can be produced in the multi- legs system.

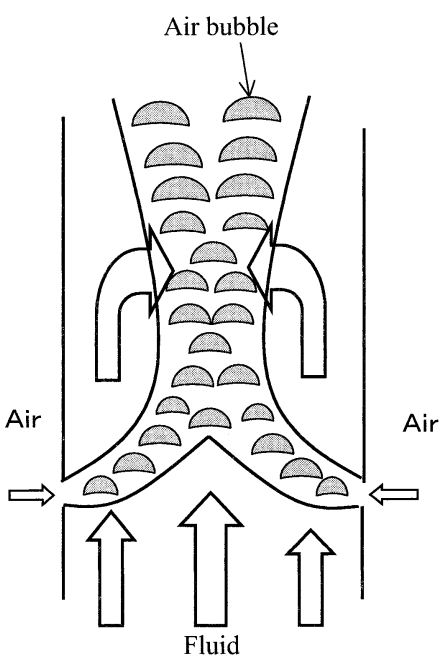

Fig. 10. Flow induced by air bubbles in the up-leg.

Two- legs
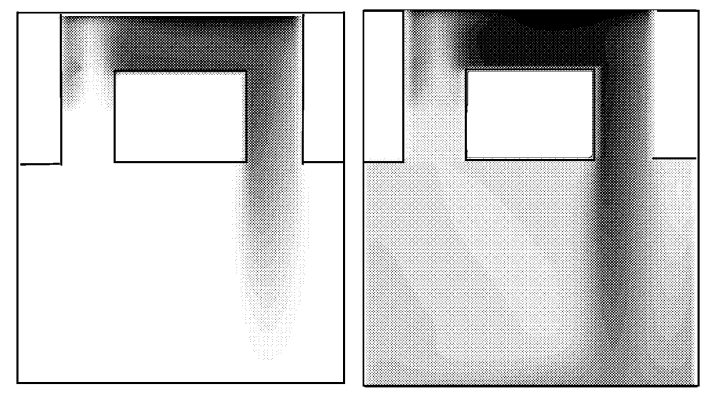

Multi- legs

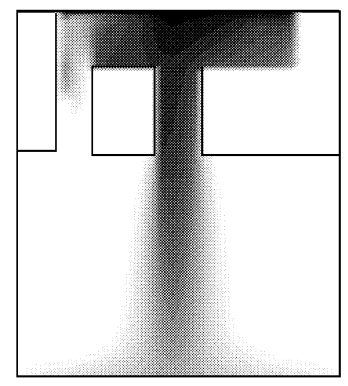

(a)

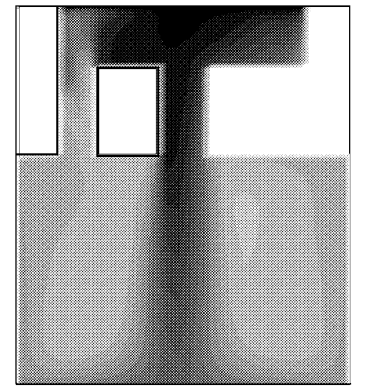

(b)
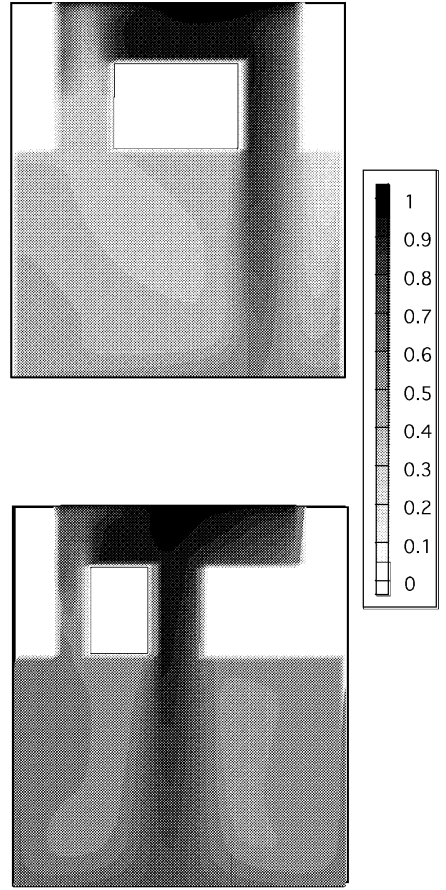

(c)

Fig. 11. Transient concentration profiles of the two- and multi-legs RH degassing vessel at times (a) $10 \mathrm{~s}$, (b) $100 \mathrm{~s}$, and (c) $180 \mathrm{~s}$. 


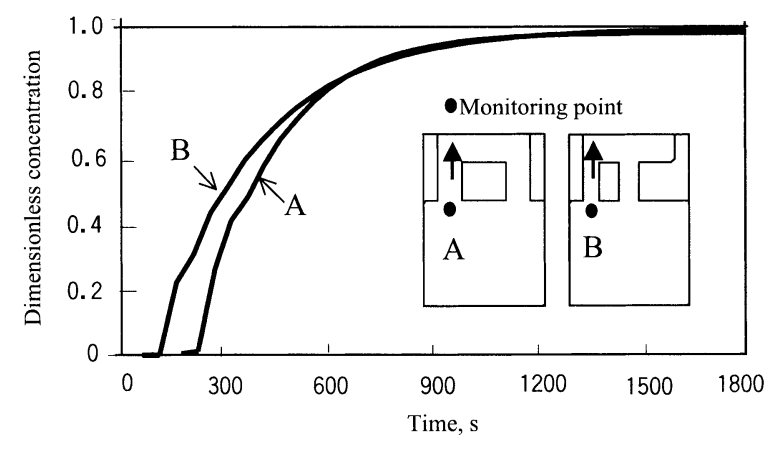

Fig. 12. Comparison of tracer concentration varies with time between two- and multi-legs systems.

To clarify the difference of circulating flow characteristics between two- and multi-legs systems, the transient tracer transfer is numerically simulated based on the flow field. The tracer is placed initially at the free surface of fluid. Figure 11 shows the concentration profiles at various times of the two- and multi-legs system for $35 \mathrm{l} / \mathrm{min}$ of air flowrate. The tracer in multi-legs reaches to the bottom of ladle at $10 \mathrm{~s}$. However, it does not reach to the bottom for two-legs. The transfer speed of tracer in multi-legs system is remarkably faster than that of two-legs system. Figure 12 shows that comparison of concentration values at point $\mathrm{A}$ and $\mathrm{B}$ of two- and multi-legs system. The high transfer rate with the multi-legs system has been observed.

\section{Conclusions}

A mathematical model for flow phenomena of water model of RH degassing vessel with two- and multi-legs has been developed, and a gas plume model with the effect of gas expansion during the floatation of bubbles was proposed and the following conclusions are obtained.

(1) The calculated velocities at the outlet of down-leg agree well with measured values for both of two- and multilegs RH system of water model.

(2) Flow fields of two- and multi-legs systems have been calculated. The velocity profile with multi- legs is uniform, and the mean velocity in ladle is remarkably larger than that with two-legs, and the maximum velocity with multi-legs is smaller than that with two-legs. The same tendency also was observed from the calculation of the turbulent kinetic energy.

(3) If large amount of air is injected into one up-leg such as two-leg RH degassing vessel, the space occupied by air bubbles prevents the fluid flowing through up-leg. If air is injected through three legs as multi-legs system, the three up-legs can allow more fluid flow.
(4) Transfer speed of tracer in multi-legs system is remarkably faster than that of two-legs system, since the RH degassing vessel with multi-legs can produce more strong momentum transfer.

\section{Nomenclature}

$C$ : the concentration of tracer

$D$ : the inlet diameter of air plume (m)

$D_{0}$ : diameter of the vacuum vessel (m)

$D_{1}$ : diameter of the down-leg (m)

$d: \quad$ inlet diameter of air plume (m)

$g$ : acceleration due to gravity $\left(\mathrm{m} / \mathrm{s}^{2}\right)$

$k$ : turbulent kinetic energy $\left(\mathrm{m}^{2} / \mathrm{s}^{2}\right)$

$n$ : normal direction (m)

$p:$ pressure $\left(\mathrm{N} / \mathrm{m}^{2}\right)$

$\mathrm{P}$ : mesh node point

$t:$ time (s)

$x, y, z:$ the Cartesian coordinates (m)

$u, v, w:$ the velocity component $(\mathrm{m} / \mathrm{s})$

$V:$ finite volume $\left(\mathrm{m}^{3}\right)$

$\vec{V}:$ the total velocity $(\mathrm{m} / \mathrm{s})$

$w_{\max }$ : the maximum velocity in the outlet of the down-leg $(\mathrm{m} / \mathrm{s})$

$\alpha$ : gas volume fraction

$\varepsilon$ : the rate of dissipation of turbulent kinetic en$\operatorname{ergy}\left(\mathrm{m}^{2} / \mathrm{s}^{3}\right)$

$\mu_{\mathrm{L}}, \mu_{\mathrm{t}}, \mu_{\mathrm{e}}$ : laminar, turbulent and effective viscosity ( $\mathrm{N}$. $\left.\mathrm{s} / \mathrm{m}^{2}\right)$

$v_{\mathrm{L}}, v_{\mathrm{e}}$ : laminar and turbulent kinematic viscosity $(\mathrm{N}$. $\mathrm{s} \cdot \mathrm{m} / \mathrm{kg}$ )

$\rho, \rho_{\mathrm{g}}, \rho_{\text {liq }}:$ mixture, gas and liquid density $\left(\mathrm{kg} / \mathrm{m}^{3}\right)$

$\sigma_{\mathrm{C}}, \sigma_{k}, \sigma_{\varepsilon}$ : Schmidt numbers of the concentration, turbulent kinetic energy and its dissipation rate

\section{REFERENCES}

1) K. Nakanishi, J. Szekely and C. W. Chang: Ironmaking Steelmaking, 3 (1976), 115.

2) Y. Kato, H. Nakato, T. Fujii, S. Ohmiya and S. Takatori: ISIJ Int., 33 (1993), 1088.

3) Y. Miki, Y. Shimada, B. G. Thomas and A. Denissov: Iron Steelmaker, 24 (1997), 31.

4) F. Obata, R. Waka, K. Uehara, K. Ito and Y. Kawata: CAMP-ISIJ, 12 (1999), 166.

5) F. Obata, R. Waka, K. Uehara, K. Ito and Y. Kawata: Tetsu-toHagané, 86 (2000), 225.

6) F. Obata, R. Waka, K. Uehara, K. Ito and Y. Kawata: CAMP-ISIJ, 13 (2000), 93.

7) A. H. Castillejos and J. K. Brimacombe: Metall. Trans. B, 18B (1987), 659

8) B. E. Launder and D. B. Spalding: Computer Methods Appl. Mech. Eng., 3 (1974), 269. 